\title{
In vivo modulation of innate resistance to Edwardsiella ictaluri with a phosphatase inhibitor
}

\author{
Donald L. Evans ${ }^{1, *}$, Emmett B. Shotts ${ }^{2}$, Liliana Jaso-Friedmann ${ }^{1}$ \\ ${ }^{1}$ Department of Medical Microbiology and Parasitology, College of Veterinary Medicine, University of Georgia, Athens, \\ Georgia 30602, USA \\ ${ }^{2}$ National Fish Health Laboratory, Kearneysville, West Virginia 25430, USA
}

\begin{abstract}
Catfish were treated with the protein phosphatase inhibitor sodium orthovanadate (vanadate) and challenged with the pathogen Edwardsiella ictaluri to investigate the relationship between the in vivo immunoregulatory effects of tyrosine and serine phosphatases on nonspecific modulation of resistance to bacterial infections. Two different infection protocols were used: fish were pretreated by immersion in vanadate and subsequently infected (by immersion) with 1 LD ${ }_{100}$ E. ictaluri, or fish were injected (intraperitoneally, IP) with bacteria and simultaneously treated (by immersion) with $25 \mu \mathrm{M}$ vanadate. In the absence of vanadate, both infection models produced fulminant infection by 10 or $6 \mathrm{~d}$, respectively. Zero to $48 \mathrm{~h}$ treatment with vanadate (by immersion) prior to infection produced 17 to $100 \%$ survival of infected fish. In addition to augmentation of innate immunity, vanadate enhanced acquired immunity to this pathogen. Fish which had vanadate-induced resistance to primary infection were 'immune' to secondary challenge with a $L_{100}$ of E. ictaluri. Experiments were done to determine the mechanism(s) of the altered innate resistance. Catfish were injected (IP) with E. ictaluri and simultaneously treated (by immersion) with $25 \mu \mathrm{M}$ vanadate. Assays were done to measure nonspecific cytotoxic cell (NCC) activity at $0,24,48,72$ and $96 \mathrm{~h}$ post-infection/vanadate treatment. Increased NCC activity at 48 to $96 \mathrm{~h}$ post-infection appeared to correlate with resistance to bacterial related mortality. These data indicated that in vivo vanadate treatment of catfish significantly increased resistance to otherwise fulminant $E$. ictaluri infections. This effect coincided with the initiation of resistance to secondary infections without additional vanadate treatments. Vanadate-modulated resistance in catfish may be associated with augmented NCC activity.
\end{abstract}

KEY WORDS: Phosphatases - Phosphatase inhibitors - Edwardsiella ictalurj - Nonspecific cytotoxic cells Innate immunity $\cdot$ Cytotoxicity $\cdot$ Sodium orthovanadate

\section{INTRODUCTION}

The mechanisms of primary acquired immunity to Edwardsiella ictaluri infections in catfish have not been determined. Most studies (Wolters \& Johnson 1994) demonstrated a lack of correlation between survival from $E$. ictaluri infection and antibody levels. In many cases the highest survival rates always correlated with the lowest antibody titers (Ciembor et al. 1995). In an effort to determine other mechanisms of innate immunity to infectious disease processes in catfish, we have previously shown (Graves et al. 1985a, b) that the mammalian NK cell equivalent in catfish (i.e.

•E-mail: devans@calc.vet.uga.edu nonspecific cytotoxic cells: NCC) recognizes a membrane protein (NK target cell antigen: NKTag) on the protozoan parasite Tetrahymena pyriformis. Cold target inhibition studies demonstrated that NKTag was expressed on several NK-sensitive tumor target cells as well as on the parasite Ichthyophthirius multifiliis. In vitro and in vivo studies (Jaso-Friedmann et al. 1996, 1997) indicated that NCC may be involved in the development of innate resistance to protozoan infections by recognition of NKTag and direct lysis of cells expressing this membrane antigen.

In the present study the relationship between nonspecific amplification of innate resistance and susceptibility to Edwardsiella ictaluri mortality was investigated. NCC were stimulated in vivo with the tyrosine/ serine phosphatase inhibitor sodium orthovanadate 
(vanadate) to determine the role of these cells in mediating nonlytic innate responses. We previously demonstrated (Evans \& Jaso-Friedmann 1994) that in vitro treatment of purified NCC with vanadate produced a significant increase in the lysis of IM-9 target cells. This indicated that certain phosphatases may regulate receptor-mediated activation of NCC. The relevance of tyrosine phosphatase activity in mediating cytotoxicity was recently confirmed for human NK cells (Burshtyn et al. 1996). Activation of tyrosine phosphatases following killer inhibitory receptor (KIR) occupancy may be required for the immunoregulatory negative control of human NK cell activity.

Because of the extreme toxicity consequences as well as a general lack of specificity of most phosphatase inhibitors (such as okadaic acid and sodium fluoride), in vitro as well as in vivo treatment of cells with phosphatase inhibitors has not previously been attempted in any species. In the present study, we determined the nontoxic therapeutic dose of vanadate for total body immersion treatment of catfish for initiation of innate resistance to Edwardsiella ictaluri. Using a primary and secondary bacterial challenge infection model, the efficacious use of vanadate was demonstrated for the initiation of significant reductions in morbidity and mortality. One target of the vanadate action appeared to be nonspecific cytotoxic cells (NCC). Evidence to support this hypothesis was shown by demonstrating functional activation of NCC in vanadate treated and infected fish.

\section{MATERIALS AND METHODS}

Fish. Ictalurus punctatus (catfish) of both sexes, weighing 10 to $30 \mathrm{~g}$, were obtained from a commercial farm (Owen and Williams Fish Farm, Inc., Hawkinsville, GA, USA). For at least $30 \mathrm{~d}$ before use in the experiments, these outbred fish were maintained in 100 to 150 gallon (380 to 570 l) (flow-through) fiberglass holding aquaria at ambient temperatures (17 to $25^{\circ} \mathrm{C}$ ). The diet consisted of pelleted fish feed (No. 4 salmon starter, Ziegler Bros, Inc., Gardners, PA, USA).

NCC purification. Fish were net-captured and euthanized and the anterior kidney (AK) tissue (mammalian bone marrow equivalent) was removed. Single cell suspensions were prepared by standard techniques (Graves et al. 1985a). Briefly, red cells were removed by centrifugation at $650 \times g$ for $20 \mathrm{~min}$ on a cushion of $45.5 \%$ Percoll (Sigma Chemicals, St. Louis, MO, USA) in phosphate buffered saline (PBS). Cells at the top of the cushion were collected, washed once and resuspended in RPMI.

Treatment of fish with sodium orthovanadate. Fish were treated with sodium orthovanadate (vanadate)
(Sigma, S6508, Lot 52H0326) by immersion in 10 gallon (38 l) glass fish tanks. Temperature was maintained at 23 to $27^{\circ} \mathrm{C}$. Fish were treated for up to $48 \mathrm{~h}$ prior to infection or at the time of infection.

Infection with Edwardsiella ictaluri. An isolate (strain FCD) of E. ictaluri was recovered from diseased catfish exhibiting classic signs of enteric septicemia. Bacteria were prepared by growing the culture on $5 \%$ bovine blood agar $\left(30^{\circ} \mathrm{C}, 48 \mathrm{~h}\right)$. To prepare bacteria for the immersion solution or for injection, growth was removed and diluted in sterile deionized water containing sodium thiosulfate. The suspension was adjusted to an optical density of 0.515 to 0.523 using a Beckman Model 64 spectrophotometer (520 lambda). For bacterial enumeration, serial log dilutions were plated on $5 \%$ bovine blood agar $\left(30^{\circ} \mathrm{C}, 48 \mathrm{~h}\right)$. Colony forming units $\mathrm{ml}^{-1}$ of inoculum was calculated by counting at extinction the total colonies present in each sample times the log dilution. One ml of stock solution contained approximately $10^{7}$ bacteria. The bacterial suspension was adjusted as needed by dilution. For immersion ( $1 \mathrm{LD}_{100}$ ), fish were treated with 1 to $3 \mathrm{l}$ of undiluted stock solution for 30 to $45 \mathrm{~min}$ (room temperature with aeration). For injection, $1 \mathrm{LD}_{1.00}$ consisted of $100 \mu \mathrm{l}$ of a 1:3 dilution of the stock solution (containing approximately $3 \times 10^{5}$ bacteria) given intraperitoneally (IP). All treated and control catfish were maintained at 23 to $27^{\circ} \mathrm{C}$ water temperature. Immersion and intraperitoneal injection protocols are representative of 8 and 3 experiments using more than a total of 500 catfish (replicates of 8 to 32 fish per tank).

Cell-mediated cytotoxicity. A chromium ${ }^{51}$ release assay was used to determine cytotoxicity. The target cell used in the cytotoxicity assays was IM-9 human Blymphoblast (ATCC $i$ CCL 159). Prior to labelling, cells were maintained in tissue culture containing RPMI1640 (10\% fetal bovine serum) in log phase growth $\left(37^{\circ} \mathrm{C}, 5 \% \mathrm{CO}_{2}\right)$.

\section{RESULTS}

\section{Effects of vanadate on Edwardsiella ictaluri morbidity and mortality}

Experiments were first conducted to determine the acute toxicity effects of different concentrations of vanadate on catfish. Fish maintained at 23 to $27^{\circ} \mathrm{C}$ in 301 of dechlorinated and aerated water were treated with 15 to $100 \mu \mathrm{M}$ vanadate. Concentrations of 75 to $100 \mu \mathrm{M}$ were lethal (data not shown). Next, experiments were done to determine the effects of vanadate on NCC activity in the absence of bacterial infection. Temperature-acclimated fish were treated (by immersion) with $50 \mu \mathrm{M}$ vanadate and, at $10,24,48$ and $72 \mathrm{~h}$ 


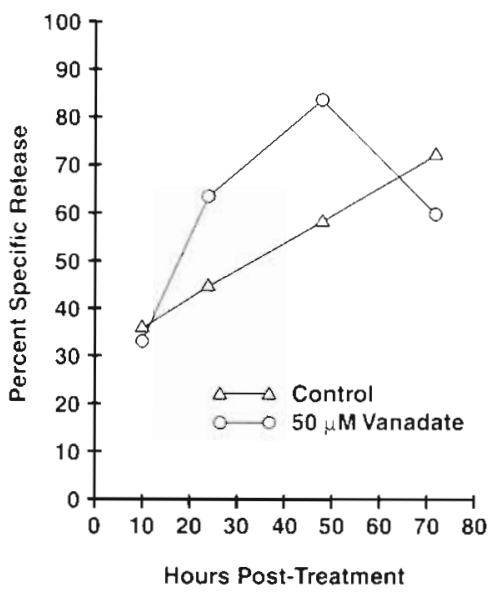

Fig. 1. Ictalurus punctatus. Effects of in vivo vanadate treatment on NCC activity. Catfish were treated by immersion in $50 \mu \mathrm{M}$ vanadate, and at $10,24,48$ and $76 \mathrm{~h}$ (post-treatment) fish were sacrificed and NCC from the anterior kidney were tested (effector:target cell ratio 80:1) for cytotoxicity against chromium $^{51}$ labelled IM-9 target cells

post-treatment, NCC activity was determined. At 24 and 48 h, NCC activity of vanadate-treated (but noninfected) fish was significantly higher than that of controls (Fig. 1). Cytotoxicity returned to control levels by $72 \mathrm{~h}$ post-treatment.

To determine if vanadate pretreatment of fish produced any effects on innate levels of resistance to bacterial pathogens, fish were treated with 25 and $50 \mu \mathrm{M}$ vanadate for $48 \mathrm{~h}$ and then infected (by immersion) with Edwardsiella ictaluri. Fig. 2 A shows that all nonvanadate-treated and infected fish died by $10 \mathrm{~d}$ postinfection. The 25 and $50 \mu \mathrm{M}$ vanadate-pretreated fish had $50 \%$ and $17 \%$ survival respectively. The level of secondary anti-bacterial resistance of the $25-\mu \mathrm{M}$ vanadate-treated survivors (i.e. 16 of 32 fish from Fig. 2) was determined by infection of these fish with $1 \mathrm{LD}_{100}$ of E. ictaluri $21 \mathrm{~d}$ following the primary infection of the fish (shown in Fig. 2A). Fig. 2B shows a greater than $90 \%$ survival of fish which had previously been treated with $25 \mu \mathrm{M}$ vanadate. These fish did not receive additional vanadate treatment. Direct bacterial toxicity experiments treating $E$. ictaluri with $25 \mu \mathrm{M}$ vanadate showed no effects on bacterial growth (data not shown). Additional experiments were conducted to isolate E. ictaluri from the trunk kidney of infected fish. These isolates exhibited pathogenicity identical to that of the test bacteria (data not shown).

In order to insure that all fish were infected with the same number of bacteria, to standardize the prepatent period from injection to onset of mortality, and to establish a time course for morbidity and mortality such that certain immune and biochemical parameters could be measured, experiments were next done to
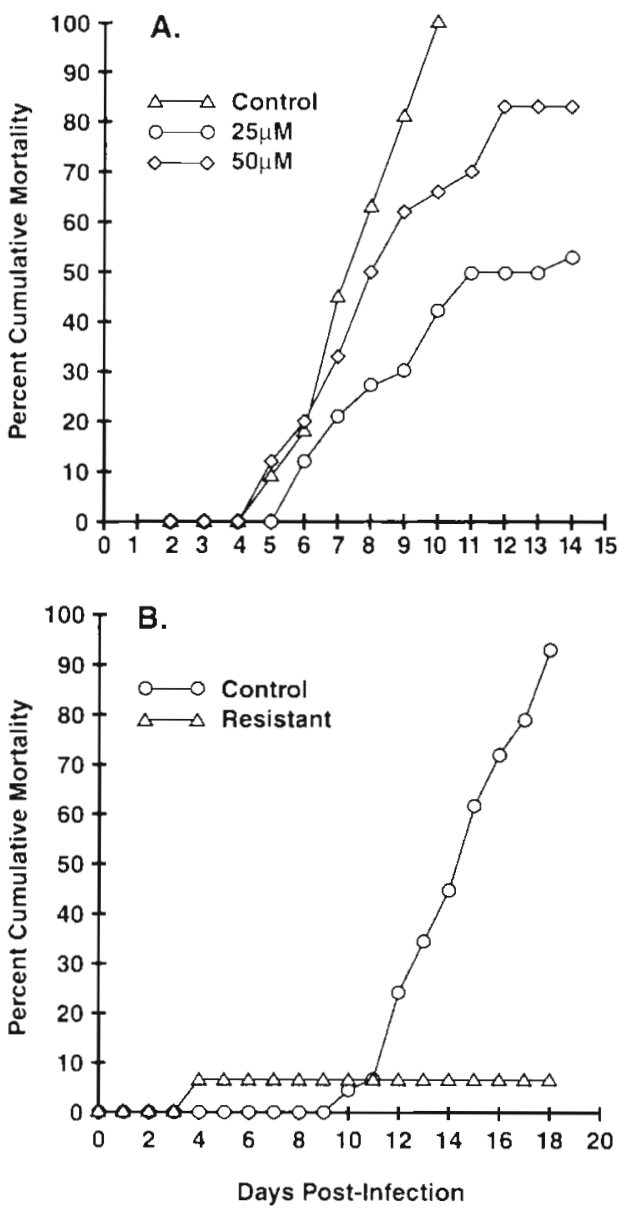

Fig. 2. Ictalurus punctatus. Effects of pretreatment of catfish with vanadate on Edwardsiella ictaluri-induced mortality. Fish were treated by immersion in 25 and $50 \mu \mathrm{M}$ vanadate $48 \mathrm{~h}$ prior to infection (by immersion) with E ictaluri. (A) Cumulative mortality and (B) secondary responses of the 25- $\mu \mathrm{m}$ vanadate-treated ('resistant') fish which were challenged $21 \mathrm{~d}$ later with $1 \mathrm{LD}_{100}$ dose of E. ictaluri. Control fish in (B) were not pretreated with vanadate and had not been previously infected

determine the effects of vanadate pretreatment on IP injection with Edwardsiella ictaluri. Fig. 3 shows that both 24 and 0 h pretreatments with $25 \mu \mathrm{M}$ vanadate produced significant protection against $E$. ictaluri IP injection. The prepatent period was reduced from 10 to approximately $6 \mathrm{~d}$.

Experiments were next done to repeat the data shown in Fig. 2 except that an IP injection protocol was used. Catfish were treated with $25 \mu \mathrm{M}$ vanadate for 0 (i.e. at time of injection) or $18 \mathrm{~h}$ and then injected $\mathrm{IP}$ with $100 \mu \mathrm{l}$ Edwardsiella ictaluri. Fig. 4A shows catfish treated with $25 \mu \mathrm{M}$ vanadate for 0 or $18 \mathrm{~h}$ prior to IP injection with $100 \mu$ l containing approximately $3 \times$ $10^{5}$ bacteria. For these fish $100 \%$ survival of $0 \mathrm{~h}$ and approximately $40 \%$ survival of $18 \mathrm{~h}$ vanadatepretreated fish was observed. All non-treated/infected 


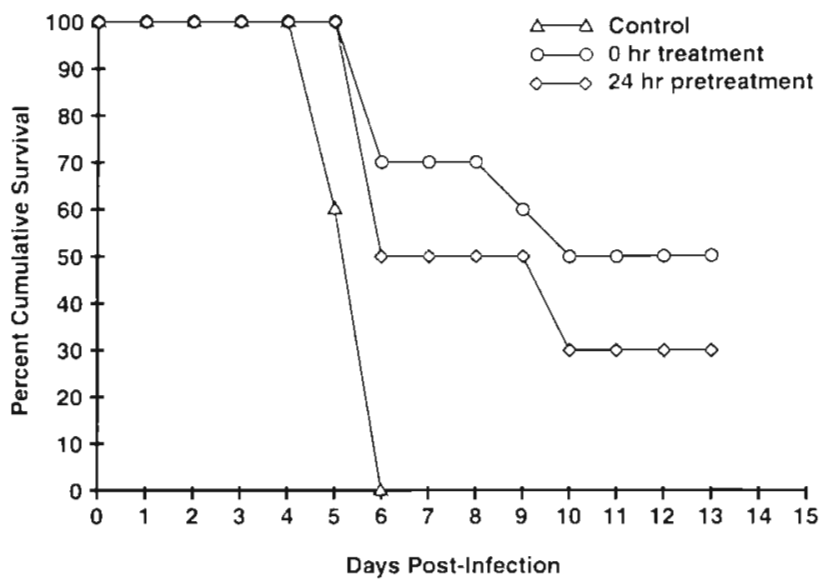

Fig. 3. Ictalurus punctatus. Effects of vanadate treatment on the survival of catfish following IP injection with Edwardsiella ictaluri. Catfish were either not treated (control) or treated with $25 \mu \mathrm{M}$ vanadate for 0 (i.e. at time of injection) or $24 \mathrm{~h}$ prior to IP injection of E. ictaluri. All non-treated controls died by $6 \mathrm{~d}$ following injection. Vanadate-treated catfish had 50 and $30 \%$ survival following 0 and $24 \mathrm{~h}$ pretreatment

controls died by 6 d post-infection. Surviving fish from Fig. $4 \mathrm{~A}$ were challenged with $1 \mathrm{LD}_{100}$ E. ictaluri (Fig. 4B). This was done $34 \mathrm{~d}$ following the first IP injection. These fish did not receive a second vanadate treatment. All fish survived compared to almost $90 \%$ mortality in the non-treated/naive control fish.

\section{Effects of vanadate and Edwardsiella ictaluri on NCC activity}

Experiments were conducted to determine if vanadate-treated and infected fish had increased innate immune responses as measured by determination of changes in the level of NCC activity. Fish were treated with $25 \mu \mathrm{M}$ vanadate and infected with $1 \mathrm{LD}_{100}$ Edwardsiella ictaluri on Day 0. NCC lytic activity, NCC numbers in the anterior kidney and cellularity of the anterior kidney were determined at Days 0 to 4 post-treatment. Fig. 5 shows the NCC cytotoxicity at 0 . 2 and $4 \mathrm{~d}$ post-treatment. Although wide variability was observed in the cytotoxicity profiles of each group (40:1 effector:target cell ratio), control non-infected (Group 1, Fig. 5) and non-vanadate-treated but infected (Group 2) fish had lower cytotoxicity levels than vanadate-treated and infected fish (Group 4). The cumulative mortality of the positive infection control group (insert, Fig. 5) shows $100 \%$ mortality by $7 \mathrm{~d}$ postinfection. Peak cytotoxicity in the vanadate-treated fish occurred at $48 \mathrm{~h}$ (Day 2) post-treatment. This coincided with onset of $E$. ictaluri morbidity in nonvanadate-treated fish. The percent composition of NCC in the anterior kidney as determined by cell size (e.g NCC are 4 micron cells) and total cell enumeration of the anterior kidney at each experimental time point revealed no differences between control and vanadate-treated fish (data not shown).

\section{DISCUSSION}

We were the first to describe the in vitro modulatory effects of protein tyrosine and serine/threonine phosphatase inhibitors on cytotoxicity (Evans \& JasoFriedmann 1994, Jaso-Friedmann 1994). In one study (Evans \& Jaso-Friedmann 1994), NCC activity from 'stressed' fish (stress defined as the absence of NCC activity without obvious clinical signs and symptoms
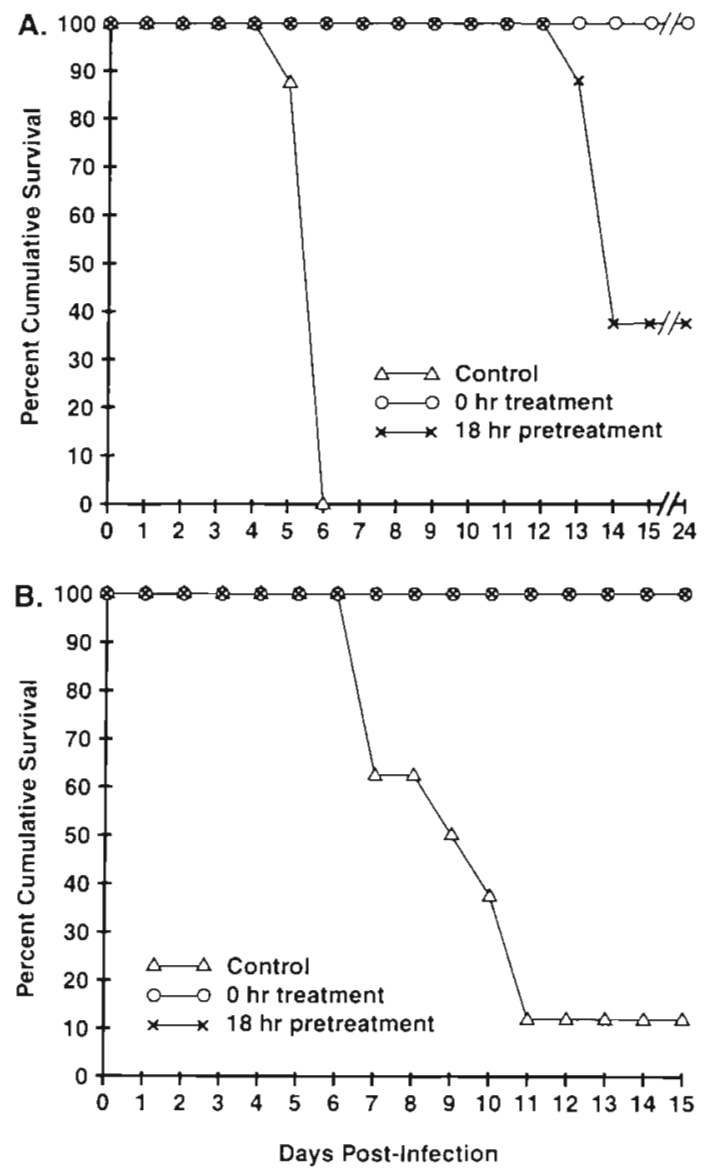

Fig. 4. Ictalurus punctatus. Effects of vanadate treatment on catfish mortality following IP infection with Edwardsiella ictaluri. Catfish were treated for 18 and $0 \mathrm{~h}$ with $25 \mu \mathrm{M}$ vanadate and then infected by IP injection. (A) $100 \%$ of the $0 \mathrm{~h}$, and approximately $40 \%$ of 18 h vanadate-pretreated fish survived. (B) Vanadate-treated survivors from (A) were challenged with E. ictaluri. Greater than $90 \%$ mortality was seen in controls (non-vanadate-treated) compared to $0 \%$ mortality in vanadate-pretreated fish 

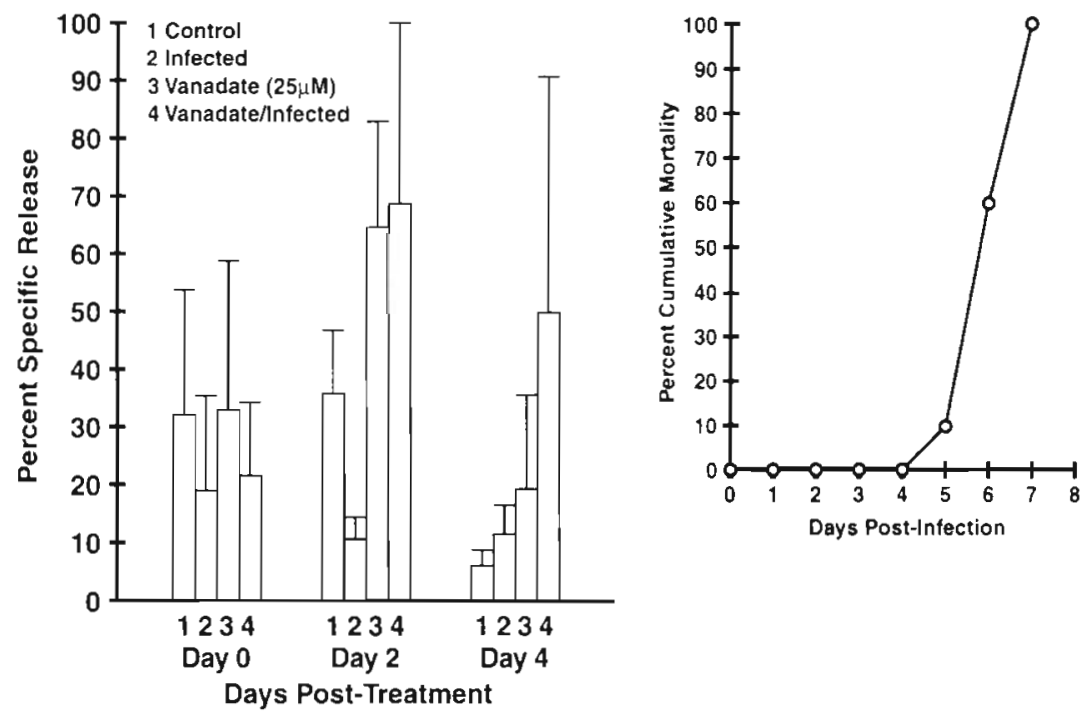

Fig. 5. Ictalurus punctatus. Effects of in vivo vanadate treatment and Edwardsiella ictaluri infection on NCC cytotoxicity. Four groups of fish were tested following 0,48 (Day 2) and 96 h (Day 4) of treatment. Treatments were controls (Group 1), infected (Group 2), $25 \mu \mathrm{M}$ vanadate treated only (Group 3) and vanadate treated and infected (Group 4). NCC were purified from anterior kidney tissue, and at each day post-treatment. NCC from 2 identical treatment fish were pooled and tested for cytotoxicity against labelled IM-9 target cells. Each bar represents the mean (+ SE) of cytotoxicity values from separate experiments (2 fish pooled in each experiment for a total of 6 fish). Effector:target cell ratio was 40:1 and cytotoxicity experiments were 4 h. Control cytotoxicity from 'holding tank' controls (i.e. stock population of fish from which experimental fish were obtained) was approximately $30 \%$ (40:1 effector:target cell ratio). Mortality profile of control infected fish is also shown (right graph)

from bacterial or protozoan diseases) was activated (in vitro) up to 20 -fold with 25 or $100 \mu \mathrm{M}$ sodium orthovanadate. In vitro treatment of NCC with vanadate for as little at $2 \mathrm{~h}$ produced significant increased lysis of chromium-labelled IM-9 target cells (Evans \& JasoFriedmann 1994). In vivo treatment of fish with $50 \mu \mathrm{M}$ vanadate produced significant increased cytotoxicity at $48 \mathrm{~h}$ post-treatment. Although these studies were conducted without an additional infectious disease insult, the data indicated that fish stressed by infection with a highly pathogenic microorganism might have augmented cytotoxicity if treated in vivo with nontoxic levels of vanadate.

Both cytotoxic T-lymphocyte and NK cell cytotoxicity is increased by in vitro treatment with okadaic acid (OK) (Taffs et al. 1991, McVicar et al. 1994). Although lytic activity was affected by nanomolar concentrations, OK was very toxic at slightly higher concentrations. In vivo studies were not feasible because of this consequence. Levels of vanadate closely approximating those used in the present study $(30 \mu \mathrm{M})$ were used to demonstrate activation of lymphoblastic proliferation of human T-cells (Levanainen et al. 1990). These studies clearly demonstrated that inhibition of the dephosphorylation of certain signalling proteins in cytotoxic cells significantly affects the ability of these cells to lyse targets. This alteration in the phosphorylation status apparently does not affect target cell binding or membrane receptor expression. Purified NCC from Edwardsiella ictaluri-infected fish did not have diminished percentage expression of mab 5C6 (a cross-species reactive mab which recognizes NCC and mammalian NK cells; Evans et al. 1988), nor was there a decrease in absolute numbers of NCC in the anterior kidney of these fish (data not shown). These data suggested that conjugate formation was not completely sufficient for target cell lysis, but NCC required 'downstream' protein phosphorylation to complete the lytic cycle. This enabled both innate and acquired mechanisms to initiate protection from E. ictaluri morbidity/mortality.

Acknowledgements. Research work supported by USDA grant 92-03552-05.

\section{LITERATURE CITED}

Burshtyn DN, Scharenberg AM, Wagtmann N, Rajagopalan S, Berrada K, Yi-T, Kinet JF, Long EO (1996) Recruitment of tryosine phosphatase HCP by the killer cell inhibitor receptor. Immunity 4:77-85

Ciembor PG, Blazer VS, Dawe D, Shotts EB (1995) Susceptibility of channel catfish to infection with Edwardsiella ictaluri: effect of exposure method. J Aquat Anim Health $7: 132-140$

Evans DL, Jaso-Friedmann L (1994) Role of protein phosphatases in the regulation of nonspecific cytotoxic cell activity. Dev Comp Immunol 18:137-144

Evans DL, Smith EE, Jaso-Friedmann L, St. John A, Koren HS, Harris DT (1988) Identification of a putative antigen 
receptor on fish nonspecific cytotoxic cells with monoclonal antibodies. J Immunol 141:324-332

Graves SS, Evans DL, Dawe DL (1985a) Antiprotozoan activity of nonspecific cytotoxic cells (NCC) from the channel catfish (Ictalurus punctatus). J Immunol 134:78-88

Graves SS, Evans DL, Dawe DL (1985b) Mobilization and activation of nonspecific cytotoxic cells (NCC) in the channel catfish (Ictalurus punctatus) infected with Ichthyophthirius multifiliis. Comp Immunol Microbiol Infect Dis 8: $43-52$

Jaso-Friedmann L, Leary JH IIl, Evans DL (1994) Pathways of signaling in nonspecific cytotoxic cells: effects of protein kinase and phophatase inhibitors and evidence for membrane tyrosine phosphorylation. Cell Immunol 153:142-151

Jaso-Friedmann L, Leary JH III, McGraw RA, Evans DL (1997) Molecular characterization of a protozoan parasite target antigen recognized by nonspecific cytotoxic cells. Cell Immunol 176:93-102

Jaso-Friedmann L, Leary JH III, Weisman Z, Evans DL (1996)

Editorial responsibility: Otto Kinne,

Oldendorf/Luhe, Germany
Activation of nonspecific cytotoxic cells with a multiple antigenic peptide: specificity and requirements for receptor crosslinkage. Cell Immunol 170:195-210

Levanainen AV, Lindquist C, Mustelın T, Anderson LC (1990) Phosphotyrosine phosphatases are involved in reversion of $T$ lymphoblastic proliferation. Eur J Immunol 20: 2509-2512

McVicar DW, Mason AT, Bere EW, Ortaldo JR (1994) Activation of peripheral large granular lymphocytes with the serine/threonine phosphatase inhibitor, okadaic acid. Eur J Immunol 24:165-170

Taffs RE, Redegeld FA, Sitkovsky MV (1991) Modulation of cytolytic $T$ lymphocyte functions by an inhibitor of serine/threonine phosphatase, okadaic acid. Enhancement of cytolytic $T$ lymphocyte-mediated cytotoxicity. $\mathrm{J}$ Immunol 147:722-728

Wolters WR, Johnson WR (1994) Enteric septicemia resistance in blue catfish and three channel catfish strains. J Aquat Anim Health 6:329-334

Submitted: September 8, 1997; Accepted: January 23, 1998 Proofs received from author(s): April 30, 1998 